\title{
Spillovers of Health Education at School on Parents' Physical Activity
}

\author{
Lucila Berniell*, Dolores de la Mata ${ }^{\dagger}$, Nieves Valdés $\ddagger \S$
}

\begin{abstract}
To prevent modern diseases such as obesity, cancer, cardiovascular conditions and diabetes, which have reached epidemic-like proportions in the last decades, many health experts have called for students to receive Health Education (HED) at school. Although this type of education aims mainly to improve children's health profiles, it might affect other family members as well. This paper exploits state HED reforms as quasi-natural experiments to estimate the causal impact of HED received by children on their parents' physical activity. We use data from the Panel Study of Income Dynamics (PSID) for the period 1999-2005 merged with data on state HED reforms from the National Association of State Boards of Education (NASBE) Health Policy Database, and the 2000 and 2006 School Health Policies and Programs Study (SHPPS). To identify the spillover effects of HED requirements on parents' behavior we use a "differences-in-differencesin-differences" (DDD) methodology in which we allow for different types of treatments. We find a positive effect of HED reforms at elementary school on parents' probability of doing light physical activity. The implementation of HED for the first time increases fathers' probability of engaging in physical activity in 14 percentage points, although it does not seem to affect mothers' probability of being physically active. We find evidence of two channels that may drive these spillovers. We conclude that information sharing between children and parents as well as the specialization of parents in doing typically-male or female activities with their children may play a role in generating these indirect effects and in turn in shaping healthy lifestyles within the household.
\end{abstract}

JEL Classification: I12, I18, I28, C21.

Keywords: physical activity; healthy lifestyles; indirect treatment effects; health education; triple differences.

\footnotetext{
* Department of Economics, Universidad Carlos III de Madrid.

${ }^{\dagger}$ Department of Economics, Universidad Carlos III de Madrid.

${ }^{\ddagger}$ Department of Economics, Universidad de Santiago de Chile.

${ }^{\S}$ Special thanks to Pedro Albarrán, Nezih Guner, Matilde Machado and Ricardo Mora for their advice, remarks and comments. We also thank Manuela Angelucci, Giorgio Brunello, Julio Cáceres, Irma Clots, Sara de la Rica, Luis Garicano, Marcos Vera, and seminar participants at the Universidad Carlos III de Madrid, Tilburg University, Universidad de Chile, Pontificia Universidad Católica de Chile, 2010 Congress of the European Economic Association, and 2010 Annual Meeting of the Chilean Economic Society for helpful comments and discussions. We gratefully acknowledge the help of Nancy Brener (Division of Adolescent and School Health at the CDC) in understanding the information provided by the SHPPS. The usual disclaimer applies.
} 


\section{Introduction}

Non-communicable diseases such as obesity, cancer, cardiovascular conditions and diabetes have reached epidemic-like proportions in the last decades. Physical inactivity is one of the most important risk factors for these diseases (WHO, 2003). As a result, prevention increasingly involves changes in healthy lifestyles such as the regular practice of physical activity in order to reduce risk factors (Kenkel, 2000). In the US, physically active individuals save an estimated US\$ 500 per year in health care costs according to 1998 data (WHO, 2003).

Interactions within the family may crucially affect the "production" of such healthy lifestyles. As Kenkel (2000) points out, the family is often identified as being the unit of production of prevention practices. Previous literature on intra-household health decisions has focused on the interactions between spouses. ${ }^{1}$ Also, the literature on intergenerational transmission of characteristics such as health, ability, education or income, has focused on the effects that parents' decisions may have on children's behaviors and outcomes. ${ }^{2}$ Nevertheless, little research has been done to evaluate the impact of children on parents' decisions, in particular on healthy lifestyle choices.

Schools can play a fundamental role in providing children with information about healthy lifestyles and health decisions, which may complement what they learn at home. At schools, the knowledge about health is transferred to children through the implementation of specific curricular modules, often known as Health Education (HED). Although HED is likely to affect children's health behaviors it may be the case that parents are also affected by the education about preventive health care that their children acquire at school. ${ }^{3}$

The first goal of this paper is to assess the existence of spillover effects of Health Education received by children at school on their parents. ${ }^{4}$ We exploit the quasi-experiment provided by

\footnotetext{
${ }^{1}$ For instance, see Clark and Etile (2006) on spousal correlation of smoking behavior.

${ }^{2}$ There are numerous studies quantifying the role of intergenerational transmission of parents characteristics and behaviors on children outcomes (Currie, 2009).

${ }^{3}$ As stated by WHO (1999), there are several reasons for promoting healthy behaviors through schools. Schools are an efficient way to reach school-age children and their families in an organized way and also the school is a place where students spend a great portion of their time, and where education and health programs can reach them at influential stages in their lives.

${ }^{4}$ According to the Centers for Disease Control and Prevention (CDC) "Health Education is a planned, sequential, and developmentally appropriate instruction about Health Education designed to protect, promote, and enhance the health literacy, attitudes, skills, and well-being" (Kann et al., 2007).
} 
the changes in the state-level HED requirements in elementary schools implemented between school-years $1999 / 2000$ and 2005/2006 in the US to quantify the effects of these programs on parents' physical activity. ${ }^{5}$ Thus, the focus is on a policy that does not imply any transfer of resources to children -the targeted individuals- but instead it provides them with new information. A second goal of this paper is to discuss the plausible channels through which children receiving HED at schools may affect the probability with which their parents engage in physical activity.

To identify the spillover effects of HED policies we use a "differences-in-differences-indifferences" (DDD) strategy. For identification we exploit the time series and the cross sectional state variation, as well as the within state variation. We are able to exploit this third difference because in our sample we have, within each state, individuals who were exposed and others who were not exposed to the treatment. The time dimension allows to include year effects in order to capture national trends in physical activity. The variation across states allows to control for systematic differences in physical activity between people living in states that change their HED policies and people living in states that do not change their HED policies. The variation within states allows to control for state-specific time trends which can be correlated with the change in HED policies. The key assumption is that there are not other shocks that occurred contemporaneously to the HED reforms and only affected treated individuals' outcome. We use data from the Panel Study of Income Dynamics (PSID) for the period 1999-2005 merged with data on state HED reforms from the National Association of State Boards of Education (NASBE) State School Healthy Policy Database and the 2000 and 2006 surveys of the School Health Policies and Programs Study (SHPPS).

This work is related to two strands of literature. First, it is related to the literature on policy evaluation that focuses on measuring the spillover effects of policy interventions on non-targeted individuals, also known as Indirect Treatment Effects (ITE). The focus in our work is on spillovers on parents' behavior of a program targeted to children. In this literature there are few works assessing the existence of spillovers inside the household. One exception is Bhattacharya et al. (2006), who analyze the effects of the School Breakfast

\footnotetext{
${ }^{5}$ Further details on these policy reforms can be found in Section 2.
} 
Program (SBP) in the US not only on targeted children but also on adult (non-targeted) family members. They find that the SBP improves diet quality even for family members who were not directly exposed to it. ${ }^{6}$ The explanations for the existence of family spillover effects in this literature operate to the extent that the particular program loosens the family budget constraint, therefore, resources are freed up by the program and maybe redirected towards other household members. In contrast, in this paper we explore the existence of family spillovers occurring through non-budgetary channels. In this literature, there are also some works evaluating external effects arising at the community level instead of the family level. Some examples are Angelucci and Giorgi (2009), Lalive and Cattaneo (2006), and Miguel and Kremer (2004). ${ }^{7}$

The second strand of literature related to our work consists of recent research evaluating the impact of particular aspects of health education at the school level on students' health outcomes and behaviors. Cawley et al. (2007) find positive effects of physical education requirements on student physical exercise time. However, they do not find any impact on Body Mass Index (BMI) or the probability that the student is overweight. Also, McGeary (2009) assesses the effects of state-level nutrition-education program funding on the BMI, the probability of obesity, and the probability of above normal weight. Her results suggest that this funding is associated with reductions in BMI and in the probability of an individual having an above normal BMI.

We find evidence of a positive effect of HED at elementary school on fathers' probability of engaging in physical activity. In states introducing HED, the probability of being physically active for a father exposed to this policy is 14 percentage points higher than a comparable

\footnotetext{
${ }^{6}$ Jacoby (2002) and Shi (2008) also analyze the effects of policies directed to children on non-eligible members of the household. They do not find evidence of the existence of family spillover effects. Jacoby (2002) analyzes the impact of a school feeding program in the Philippines on caloric intake of targeted and non-targeted individuals inside the family, whereas Shi (2008) studies the existence of resources reallocation inside the household after a child receives a subsidy for covering the schooling fees in rural China. These two papers find evidence on the existence of intra-household flypaper effects, that is, there is no sizable reallocation of resources after a child receives the subsidy.

${ }^{7}$ Angelucci and Giorgi (2009) evaluate the existence of spillover effects of an aid program (PROGRESA) on the entire local economies (villages) where the program was implemented. Lalive and Cattaneo (2006) find that PROGRESA significantly increases school enrollment among non-eligible families in the villages and that this raise is driven by a peer effect. Miguel and Kremer (2004), using evidence from a randomized experiment, show that a deworming program substantially improved health and school participation among untreated children in both treatment schools and neighboring schools.
} 
father not affected by the policy. We find evidence that the policy has a higher effect on low educated males relative to high educated males, and on males with low socioeconomic status relative to males with high socioeconomic status.

We explore the channels behind this results, and we find two non-exclusive explanations. First, we find evidence on the existence of an "information sharing" channel. We analyze the differential impact of HED reforms on individuals with low and high education levels, and we obtain a higher effect on less educated individuals and individuals with a lower socioeconomic status. Second, we argue that the existence of a "role model" channel may explain the differential impact by parents' gender. The idea is that the role mothers and fathers play for their children in the activities they usually do together is important for this result. Parents usually spend more time with their children doing gendered activities, such as physical activity for the case of fathers. Therefore, the effect of the promotion of the advantages of doing physical activity is more likely to appear for fathers rather than for mothers. The existence of spillovers of HED on parental lifestyles indicates that the interaction between children and parents play a role in the formation of healthy lifestyles inside the household and that this fact must be taken into account to properly design policy interventions aiming to increase the acquisition of healthy lifestyles in a given community.

\section{$2 \quad$ Health Education Policies}

\subsection{Brief history of HED in US}

In the 1970s and 80s, research studies showed that healthy kids did better in school and scored higher on achievement tests. As a consequence, some states started to develop and implement HED programs in public schools. In the 1990s, educators, nationwide, realized the need for a set of national health education standards that states could use as a template. In 1995, the National Committee for Health Education Standards created seven national health education standards with K-12 benchmarks that covered the ten content areas of health, and the Centers for Disease Control (CDC) clearly stated six risky behaviors for adolescents. In 1998, the Congress urged the CDC to "expand its support of coordinated health education 
programs in schools" (Wyatt and Novak, 2000). Between 1994 and 2000 school health policies at state level generally remained unchanged, but important changes were detected between 2000 and $2006 .^{8}$

\section{$2.2 \quad$ SHPPS and NASBE}

The CDC conducts the School Health Policies and Programs Study (SHPPS) every 6 years since 1994. This is a nationwide survey that was designed to gather information on the characteristics of each school health program at the state, district, school, and classroom levels and across elementary, middle, and high schools. SHPPS analyzes eight components, including HED. ${ }^{9}$ We use the information of the HED component for elementary education from the SHPPS state-level surveys.

One important data limitation in SHPPS is that it is not possible to know the exact date on which the HED reforms took place in each state. However, we do know the changes that occurred between the two survey years, 2000 and 2006. The data collection in SHPPS starts in January of the corresponding year, which implies that SHPPS 2000 gathers information on the school-year 1999/2000 and SHPPS 2006 gathers information on the school-year 2005/2006.

Another limitation of this database is that the survey is completed by state education agency personnel, who may not be aware of the complete legislation surrounding HED policies. To overcome this limitation we complement the information provided by the SHPPS with the NASBE State School Health Policy Database. This database is a comprehensive set of laws and policies of the 50 states on more than 40 school health topics. It originally begun in 1998, and is maintained with support from the Division of Adolescent and School Health (DASH) of the CDC. The database contains brief descriptions of laws, legal codes, rules, regulations, administrative orders, mandates, standards, resolutions, and other written means of exercising authority. While authoritative binding policies are the primary focus of the database, it also includes guidance documents and other non-binding materials that provide a more detailed picture of a state's school health policies and activities. We use the

\footnotetext{
${ }^{8}$ See Kann et al. (2001) and Kann et al. (2007) for more details on these changes in policies.

${ }^{9}$ The remaining seven components are Physical education and activity, Health services, Mental health and social services, Nutrition services, Healthy and safe school environment, and Faculty and staff health promotion.
} 
NASBE Database to check and to supplement the information contained in SHPPS surveys in order to identify changes in HED requirements at the state level.

\subsection{Policies on HED: topics and enforcements}

HED policies have several dimensions, which we collapse into two variables. The first variable refers to the number of specific health education topics that elementary schools of a given state are required to teach. Table 1 shows the HED topics included as potential HED requirements. These five health topics are aimed to affect the knowledge and practice of physical activity among students. Table 10 in the Appendix shows that we only excluded from the complete list of topics potentially included in a HED curricula those related to sexual education, and HIV/violence/suicide/injury prevention.

The second variable consists of the number of specific policies implemented in order to guarantee the effective implementation of HED education requirements. We broadly refer to each one of these requirements as enforcements. Second part of Table 1 describes the specific state requirements enforcing HED. ${ }^{10}$

Table 1: HED topics and enforcements

\begin{tabular}{c|l} 
Topic Code & Description \\
\hline 1 & Alcohol- or Other Drug-Use Prevention \\
2 & Emotional and Mental Health \\
3 & Nutrition and Dietary Behavior \\
4 & Physical Activity and Fitness \\
5 & Tobacco-Use Prevention \\
\hline $\begin{array}{c}\text { Enforcement } \\
\text { code }\end{array}$ & Description \\
\hline 1 & State requires districts or schools to follow national or state \\
2 & health education standards or guidelines \\
& State requires students in elementary school to be tested \\
3 & on health topics \\
\hline
\end{tabular}

Tables 7, 8, and 9 in the Appendix summarize the HED reforms in each of the two dimensions -topics and enforcements- in all states between 1999 and 2005 according to the

\footnotetext{
${ }^{10}$ The full list of topics and requirements can be consulted in Table 10 in the Appendix.
} 
SHPPS. The implementation or modification of HED policies between 1999 and 2005 was not homogeneous across states. We have checked these HED requirements by analyzing the legislation briefs provided in the NASBE Database. After doing this we classified states according to the evolution of the number of topics and enforcements in each of them. Some states implemented topics and/or enforcements for the first time during these period, while other states, although having HED education by 1999, expanded the number of topics and/or enforcements. Given this heterogeneity, in our estimation we allow for differential impacts of each of these policies. ${ }^{11}$

\section{Data and Identification Strategy}

Our goal is to identify the spillover effects of elementary school HED policies implemented in certain states -the "experimental states"- on the behavior of parents of children of elementaryschool-age -the treatment group. Identifying this effect requires, as stated in Gruber (1994), controlling for any systematic shocks to the parents' outcome behavior in the experimental states that are correlated with, but not due to, changes in HED policies.

To do so we use a "differences-in-differences-in-differences" (DDD) approach that allows us to exploit the variation of HED policies across time (time dimension), across states (geographical dimension) and across different groups of individuals residing in the same state (individual dimension). That is, we compare the treatment individuals in experimental states to a set of control individuals in those same states and measure the change in the treatments' relative outcome, relative to states that did not change HED policies. The identifying assumption requires that there is no contemporaneous shock affecting the relative outcome of the treatment group in the same state-years as the change in the HED policy.

We analyze the impact of HED policies on the behavior of adults who have children attending elementary school using data from the PSID. It is a nationally representative longitudinal survey of individuals in the US (men, women, and children) and the family units in which they reside. Since 1999 PSID has expanded the set of health-related questions for family units' heads and wives, gathering information such as health status, health behaviors,

\footnotetext{
${ }^{11}$ See next Section for more details on the different types of treatments we allow for.
} 
health insurance, and health care expenditures. We concentrate on the indirect effect of HED policies on individuals' level of physical activity, that is one of the health behaviors reported in this survey. PSID also provides detailed information about family income as well as information on family composition and demographic variables, including age of family members, race, marital status, employment status and education. PSID covers all states.

We base our analysis on the PSID survey years 1999 and 2005, using 1999 as the prereform period. ${ }^{12}$ The DDD design we use to identify the effect of interest does not require the use of a panel, but the identification is improved by using longitudinal data. Even though we do not specify a model for panel data, in our final sample about $90 \%$ of the observations correspond to individuals in a panel.

Treated individuals, those exposed to HED policies, are adults who have children of elementary-school-age (6-10). PSID does not provide information on whether a child is attending elementary school. However, it provides information on the age of children, allowing us to determine if the individuals have children of school-age. ${ }^{13}$

The control group includes individuals who were unaffected by state HED requirements. We use as control group adults who have children of elementary-school-age (6-10) living in states that did not changed HED policies, that is, living in states that either did not implement HED policies or that even when having HED requirements in 1999 did not introduce any reform during the period. Furthermore, to control for possible correlation of state HED policies with unmeasured state trends in health and health behaviors, we use a sample of adults who have children aged 18 or younger but not of elementary-school-age as a comparison group. We group the non-treated individuals in three different control groups. We include in the Treatment-Non-Experimental group (Control 1) individuals with children of elementaryschool-age residing in non-experimental states. The Control-Experimental group (Control 2) includes individuals with children aged 18 or younger but not of elementary-school-age residing in experimental states. Finally, in the Control-Non-Experimental group (Control

\footnotetext{
${ }^{12}$ Given that the SHPPS does not provide the exact year in which HED reforms were introduced at the state level, we are not able to use the additional data available from PSID for periods 2001 and 2003.

${ }^{13}$ Notice that the dropout rate in elementary school is very low in the US, contrary to the case of secondary education. Therefore, by knowing the age of the children we are able to know whether the child is or not attending elementary education.
} 
Table 2: State groups, by policy implemented by 1999 or by 2005, and by policy reforms

\begin{tabular}{|c|c|c|c|c|c|c|c|}
\hline \multirow{2}{*}{\multicolumn{2}{|c|}{ Group }} & \multicolumn{2}{|r|}{ Topics } & \multicolumn{2}{|c|}{ Enforcements } & \multirow{2}{*}{$\begin{array}{c}\text { Num. of } \\
\text { states }\end{array}$} & \multirow[b]{2}{*}{ Observations } \\
\hline & & 1999 & 2005 & 1999 & 2005 & & \\
\hline \multirow{3}{*}{$\begin{array}{c}\text { Non- } \\
\text { Experimental }\end{array}$} & $S_{1}$ & no & no & no & no & 6 & 922 \\
\hline & $S_{2}$ & yes & yes & no & no & 6 & 2,516 \\
\hline & $S_{3}$ & yes & yes & yes & yes & 16 & 4,281 \\
\hline \multirow{3}{*}{ Experimental } & $S_{4}$ & yes & yes & yes & yes (increased) & 6 & 1,139 \\
\hline & $S_{5}$ & no & yes & no & yes & 9 & 2,021 \\
\hline & $S_{6}$ & yes & yes (increased) & yes & yes (increased) & 2 & 460 \\
\hline Total & & & & & & 45 & 11,339 \\
\hline
\end{tabular}

3) we include individuals with children above and bellow elementary-school-age residing in non-experimental states.

According to the observed type of HED policy reform described in Section 2.3, we classify states in six groups as shown in Table 2. In this Table states are sorted taking into account whether they have topics and enforcements in both years and whether they have increased or maintained the number of topics and enforcements between survey years. Table 2 also groups states in two broad sets: experimental and non-experimental states. ${ }^{14}$ The experimental states are those states that have introduced some HED reforms -by requiring for the first time topics and/or enforcements or by expanding the number of topics and/or enforcements on HED- between 1999 and 2005. There are three different types of treatments (policies) that define three types of experimental states, that we name $S_{4}$ to $S_{6}$. On the contrary, nonexperimental states are those that have not introduced any change in their HED requirements in this period, which we name $S_{1}$ to $S_{3}$.

Our final sample consists of parents of children under the age of 18 years old, women and men, that were part of the PSID in 1999 and/or in 2005. We have a database of 11,339 observations distributed across six groups of states, as described in Table $2 .{ }^{15}$ It is worth to notice that for most of the individuals we also have her/his couple in the sample. Given the way in which PSID is designed, for some of the individuals we also have another relative in the sample, for instance her/his siblings. This feature of our data makes it important to control for cluster at the family level in all the regressions.

\footnotetext{
${ }^{14}$ The complete list of states in each group is reported in Table in the Appendix.

${ }^{15}$ More details in Table 11 in the Appendix.
} 
We use light physical activity as the outcome variable. PSID respondents are asked about their physical activity habits in two questions. They first answer how often they do light physical activity and then they report the time unit that allows to measure the frequency of these activities (daily, weekly, monthly or annually). Based in these two questions we construct a variable that indicates the number of times per week individuals do light physical activity. It is an ordinal variable that assumes 44 different values, from 0 to 21 . Its histogram is presented in Figure 1. 15\% of the observations in the sample report not doing physical activity, while the remaining $85 \%$ do some positive number of light physical activity per week. Two well-differentiated mass points -at values 0 and 7- can be identified. Also, more than $23 \%$ of the total number of observations lies in the interval $(0,2]$ and other $23 \%$ are included in the interval $[2,7)$.

Figure 1: Histogram for the outcome variable: frequency of light physical activity (times per week)

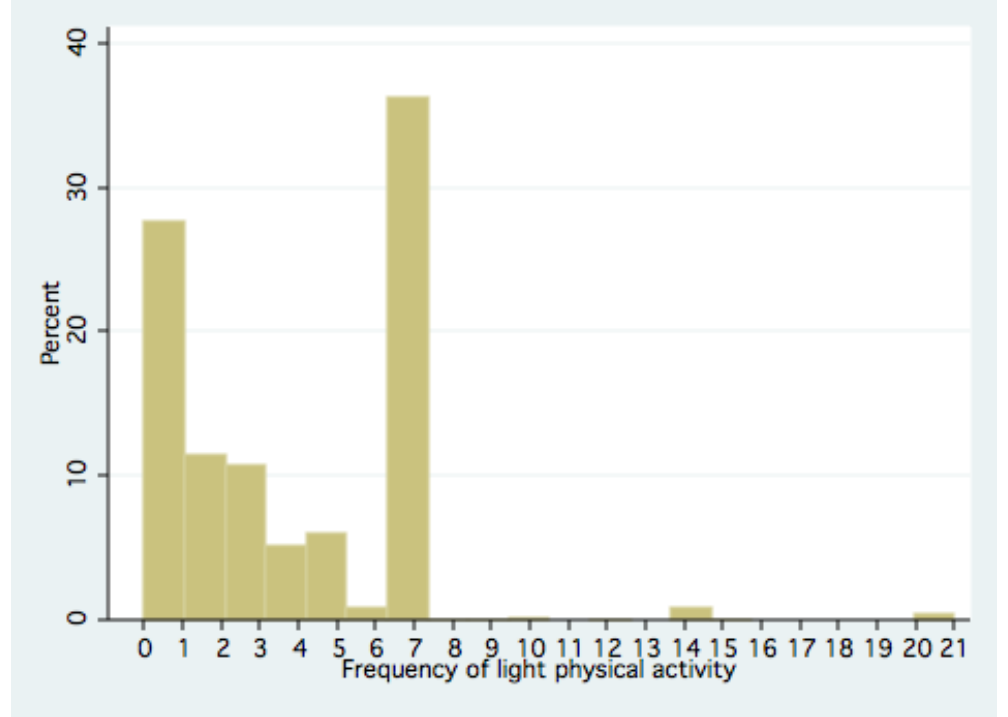

The two graphs in the left panel in Figure 2 show the average weekly frequency of light physical activity by gender in 1999 and 2005 for treated and control individuals, pooling all groups of states. We observe a downward trend in all groups for both genders. In particular, for the groups of treated individuals the frequency of light physical activity goes down. This simple Before-After estimator is telling us that HED policies have a negative impact on 
the outcome of interest. However, this estimate is obviously biased given the fact that the average of the outcome variable in the Treatment-non-Experimental group (Control 1) has also a downward trend.

Exploring gender differences we can see that females in the Treatment-Experimental group (Treated) present a larger drop in the frequency of light physical activity than that one observed for males in the same group. This fact suggests the potential need for taking into account gender differences when estimating the effect of HED policies.

Figure 2: Average frequency of light physical activity (times per week) by treatment/control (left panel), by treatment groups (right panel) and by gender, in 1999 and 2005 .
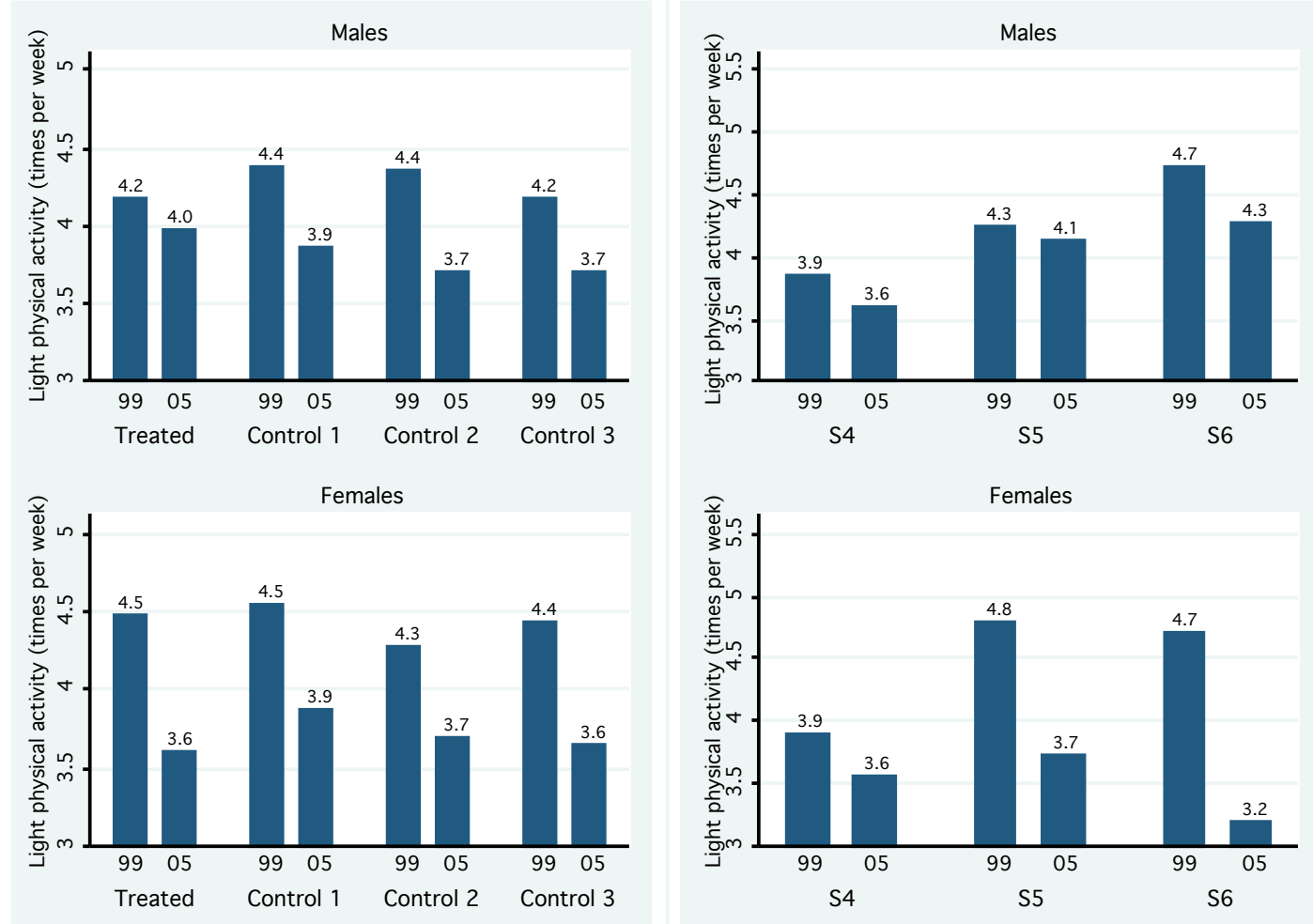

Treated: individuals with children of elementary-school-age in experimental states. Control1: individuals with children of elementary-school-age in non-experimental states. Control2: individuals without children of elementary-school-age in experimental states. Control3: individuals without children of elementary-school-age in non-experimental states. The type of policies corresponding to each group of states S are as follows. S4: topics unchanged and increase in the number of enforcements; S5: implementation of topics and enforcements; S6: increase in the number of topics and enforcements.

As we discused above, the implementation and modification of HED policies between 1999 and 2005 was not homogenous across states. For this reason we may expect differences 
in the temporal evolution of the outcome of interest for treated individuals across the three groups of states previously defined as experimental states. The two graphs in the right panel in Figure 2 show the average frequency of light physical activity for treated individuals by gender and by group of experimental states. We see that for males residing in states belonging to group $S_{5}$ the downward trend in the frequency of light physical activity is smaller than the corresponding downward trend in groups $S_{4}$ and $S_{6}$. Moreover, the reduction in the frequency of light physical activity for males in group of states $S_{5}$ is lower than the fall in the frequency of light physical activity for males in all three control groups. This moderate downward trend for treated males in $S_{5}$ experimental states suggests the existence of a positive effect of HED policies on the outcome variable.

In Table 3 we report descriptive statistics of the outcome variable, and other demographic and socioeconomic characteristics in 1999 and 2005, for all individuals in the sample.

We find evidence of statistically significant differences in some observable characteristics between 1999 and 2005, for individuals residing in Experimental and Non-Experimental states. These differences may produce changes in the observed frequency of light physical activity between 1999 and 2005, that are not a consequence of changes in HED programs. To avoid a biased estimation of the effect of interest, we use a regression framework that allow us to control for temporal differences in observable characteristics.

\subsection{DDD estimation in a simple linear model}

Table 4 presents the DDD estimate of the effect of changes in the HED policy on fathers' behavior for a particular group of states, $S_{5}$, in which both topics and enforcements where implemented between 1999 and 2005 for the first time. ${ }^{16}$ In this section we treat the outcome variable, number of times per week individuals do light physical activity, as if it were a continuous variable. With this assumption we cannot make valid quantitative interpretations of the effect of the policy, but we can still make inference regarding the sign of the effect.

The top panel compares the change in the frequency of physical activity for fathers with children of elementary-school-age residing in states $S_{5}$ to the change for fathers with children

\footnotetext{
${ }^{16}$ In Table 12 we report results for a similar exercise on mothers.
} 
Table 3: Descriptive statistics: all individuals in the sample.

\begin{tabular}{|c|c|c|c|c|c|c|}
\hline & \multicolumn{3}{|c|}{ Experimental states } & \multicolumn{3}{|c|}{ Non-Experimental states } \\
\hline & $\begin{array}{c}1999 \\
(1)\end{array}$ & $\begin{array}{l}2005 \\
(2)\end{array}$ & $\begin{array}{l}\text { Difference } \\
\quad(3)\end{array}$ & $\begin{array}{c}1999 \\
(4)\end{array}$ & $\begin{array}{c}2005 \\
(5)\end{array}$ & $\begin{array}{l}\text { Difference } \\
\quad(6)\end{array}$ \\
\hline $\begin{array}{l}\text { Frecuency of light physical } \\
\text { activity (times per week) }\end{array}$ & $\begin{array}{l}4.33 \\
(2.95)\end{array}$ & $\begin{array}{c}3.72 \\
(3.18)\end{array}$ & $-0.61^{* * *}$ & $\begin{array}{c}4.39 \\
(3.14)\end{array}$ & $\begin{array}{l}3.74 \\
(3.23)\end{array}$ & $-0.65^{* * *}$ \\
\hline Proportion of Female & $\begin{array}{l}0.57 \\
(0.50)\end{array}$ & $\begin{array}{l}0.58 \\
(0.49)\end{array}$ & 0.02 & $\begin{array}{l}0.55 \\
(0.50)\end{array}$ & $\begin{array}{l}0.56 \\
(0.50)\end{array}$ & 0.01 \\
\hline Age & $\begin{array}{c}36.52 \\
(8.09)\end{array}$ & $\begin{array}{l}39.05 \\
(9.65)\end{array}$ & $2.53^{* * *}$ & $\begin{array}{l}37.30 \\
(8.00)\end{array}$ & $\begin{array}{c}39.43 \\
(9.70)\end{array}$ & $2.13^{* * *}$ \\
\hline $\begin{array}{l}\text { Years of Education } \\
\text { completed }\end{array}$ & $\begin{array}{l}12.94 \\
(2.32)\end{array}$ & $\begin{array}{l}13.18 \\
(2.23)\end{array}$ & 0.25 & $\begin{array}{l}12.76 \\
(2.84)\end{array}$ & $\begin{array}{l}12.97 \\
(2.61)\end{array}$ & $0.21^{*}$ \\
\hline Num. of Children & $\begin{array}{l}2.29 \\
(1.23)\end{array}$ & $\begin{array}{l}2.29 \\
(1.19)\end{array}$ & 0.00 & $\begin{array}{l}2.40 \\
(1.28)\end{array}$ & $\begin{array}{l}2.37 \\
(1.22)\end{array}$ & -0.04 \\
\hline $\begin{array}{l}\text { Num. of Children } \\
\text { in elementary school }\end{array}$ & $\begin{array}{l}0.55 \\
(0.72)\end{array}$ & $(0.41)$ & $-0.13^{* * *}$ & $\begin{array}{l}0.57 \\
(0.76)\end{array}$ & $\begin{array}{l}0.41 \\
(0.66)\end{array}$ & $-0.16^{* * *}$ \\
\hline Proportion of White & $\begin{array}{l}0.56 \\
(0.50)\end{array}$ & $(0.53)$ & $-0.03^{*}$ & $\begin{array}{l}0.55 \\
(0.50)\end{array}$ & $\begin{array}{l}0.53 \\
(0.50)\end{array}$ & $-0.02^{* *}$ \\
\hline Proportion of Married & $\begin{array}{l}0.76 \\
(0.43)\end{array}$ & $\begin{array}{l}0.75 \\
(0.43)\end{array}$ & -0.01 & $\begin{array}{l}0.78 \\
(0.41)\end{array}$ & $\begin{array}{l}0.76 \\
(0.43)\end{array}$ & $-0.02^{*}$ \\
\hline Proportion of Unemployed & $\begin{array}{l}0.03 \\
(0.18)\end{array}$ & $\begin{array}{l}0.04 \\
(0.19)\end{array}$ & 0.00 & $\begin{array}{l}0.03 \\
(0.18)\end{array}$ & $\begin{array}{l}0.04 \\
(0.20)\end{array}$ & $0.01 * *$ \\
\hline Proportion of Retired & $\begin{array}{l}0.00 \\
(0.06)\end{array}$ & $\begin{array}{l}0.01 \\
(0.08)\end{array}$ & 0.00 & $\begin{array}{l}0.01 \\
(0.07)\end{array}$ & $\begin{array}{l}0.01 \\
(0.10)\end{array}$ & $0.01 * *$ \\
\hline Proportion of Disabled & $\begin{array}{c}0.02 \\
(0.13)\end{array}$ & $\begin{array}{l}0.03 \\
(0.17)\end{array}$ & $0.01^{* *}$ & $\begin{array}{l}0.02 \\
(0.14)\end{array}$ & $\begin{array}{l}0.03 \\
(0.17)\end{array}$ & $0.01 * * *$ \\
\hline $\begin{array}{l}\text { Labor income } \\
\text { (per capita) }\end{array}$ & $\begin{array}{c}13,917 \\
(13,678)\end{array}$ & $\begin{array}{c}19,092 \\
(21,944)\end{array}$ & $5,174^{* * *}$ & $\begin{array}{c}15,072 \\
(16,794)\end{array}$ & $\begin{array}{c}20,054 \\
(31,862)\end{array}$ & $4,981^{* * *}$ \\
\hline $\begin{array}{l}\text { Total income } \\
\text { (per capita) }\end{array}$ & $\begin{array}{c}16,375 \\
(15,814)\end{array}$ & $\begin{array}{c}25,711 \\
(124,101)\end{array}$ & $9,335 * * *$ & $\begin{array}{l}18,124 \\
(22,620)\end{array}$ & $\begin{array}{l}23,738 \\
(35,656)\end{array}$ & $5,613^{* * *}$ \\
\hline Sample size & 1,590 & 2,030 & & 3,394 & 4,325 & \\
\hline
\end{tabular}

Stars in columns (3) and (6) show statistical significance of differences in proportion or distribution of the referred variable, between years 1999 and 2005. We perform tests of difference in proportion for the dummy variables White, Married, Unemployment, Retired, and Disabled. We perform tests of differences in distribution for the categorical variables Frequency of light physical activity, Age, Education, Number of Children, and Number of Children in elementary school, and for the continuous variables Labor income, and Total income. Significance levels: ${ }^{*}=10 \%$; $* *=5 \% ; * * *=1 \%$. 
of elementary-school-age in non-experimental states. Each cell contains the mean average frequency of light physical activity for the group labeled on the axes, along with the standard errors and the number of observations. The Before-After estimate $\left(\Delta_{E}^{T}\right)$ of the effect is presented in the third column. There was a non-significant decrease in the frequency of light physical activity for fathers with children of elementary-school-age in experimental states, compared with a significant fall in the frequency of light physical activity for fathers with children of the same age in other states. Thus, the diff-in-diff estimator $\left(\Delta_{E}^{T}-\Delta_{N E}^{T}\right)$, reported in the bottom part of the upper panel, is positive and significant; the relative frequency of light physical activity of fathers with children of elementary-school-age has risen.

Table 4: DDD estimator for males in $S_{5}$

\begin{tabular}{|c|c|c|c|c|}
\hline & $\begin{array}{l}\text { Before HED } \\
\text { change }\end{array}$ & $\begin{array}{c}\text { After HED } \\
\text { change }\end{array}$ & $\begin{array}{c}\text { Time } \\
\text { difference }\end{array}$ & \\
\hline \multicolumn{5}{|c|}{ A. Treatment individuals: with children in elementary school } \\
\hline Experimental states & $\begin{array}{c}4.255 \\
(0.270) \\
{[150]}\end{array}$ & $\begin{array}{c}4.138 \\
(0.267) \\
{[157]}\end{array}$ & $\begin{array}{l}-0.117 \\
(0.380)\end{array}$ & $\Delta_{E}^{T}$ \\
\hline Non-experimental states & $\begin{array}{c}4.867 \\
(0.357) \\
{[59]}\end{array}$ & $\begin{array}{c}3.200 \\
(0.327) \\
{[68]}\end{array}$ & $\begin{array}{c}-1.668^{* * *} \\
(0.484)\end{array}$ & $\Delta_{N E}^{T}$ \\
\hline \multicolumn{3}{|l|}{ Difference in difference } & $\begin{array}{c}\mathbf{1 . 5 5 1 * *} \\
(0.615)\end{array}$ & \\
\hline \multicolumn{5}{|c|}{ B. Control Individuals: without children in elementary scchol } \\
\hline Experimental states & $\begin{array}{c}4.420 \\
(0.188) \\
{[229]}\end{array}$ & $\begin{array}{c}3.595 \\
(0.182) \\
{[328]}\end{array}$ & $\begin{array}{c}-0.825^{* * *} \\
(0.262)\end{array}$ & $\Delta_{E}^{C}$ \\
\hline Non-experimental states & $\begin{array}{c}4.206 \\
(0.370) \\
{[100]} \\
\end{array}$ & $\begin{array}{c}4.043 \\
(0.268) \\
{[150]} \\
\end{array}$ & $\begin{array}{l}-0.163 \\
(0.457)\end{array}$ & $\Delta_{N E}^{C}$ \\
\hline \multicolumn{3}{|l|}{ Difference in difference } & $\begin{array}{l}-\mathbf{0 . 6 6 2} \\
(0.527)\end{array}$ & \\
\hline \multicolumn{3}{|c|}{$\mathbf{D D D}=\left(\Delta_{\mathrm{E}}^{\mathrm{T}}-\boldsymbol{\Delta}_{\mathbf{N E}}^{\mathrm{T}}\right)-\left(\Delta_{\mathrm{E}}^{\mathrm{C}}-\boldsymbol{\Delta}_{\mathbf{N E}}^{\mathrm{C}}\right)$} & $\begin{array}{c}\mathbf{2 . 2 1 3}^{* * * *} \\
(0.810) \\
\end{array}$ & \\
\hline
\end{tabular}

Cells contain mean frequency of light physical activity for the group identified. Standard errors are given in parentheses, and sample sizes in brackets. The non-experimental states are groups of states S1, S2 and S3. Significance levels: ${ }^{*}=10 \% ;{ }^{* *}=5 \% ;{ }^{* * *}=1 \%$.

If there were a different shock common to the experimental states that affected fathers' frequency of physical activity, the previous estimator does not identify the spillover effects of the implementation of HED policies. In the middle panel of Table 4 we perform the same exercise for the groups of fathers with children above and bellow elementary-school- 
age. For those groups we find a fall in the relative frequency of light physical activity in the experimental states, relative to the other states. Although not significant, this suggests that it may be important to control for state-specific shocks in estimating the impact of HED policies.

Taking the difference between the two panels of Table 4, we obtain a significant increase in the relative frequency of physical activity for fathers of children in elementary-school-age in the states that implemented HED requirements, compared to the change in the relative frequency of physical activity in non-experimental states. This statistically significant DDD estimate provides some evidence on the existence of spillovers of HED on fathers' physical activity. However, its quantitative interpretation is problematic since the support of the outcome variable is not the real line. We discuss in the next Section how the DDD design can be expressed within a regression framework in which we can explicitly model the discrete support of the outcome variable as well as we can control for observed characteristics.

\subsection{Empirical model}

Our outcome variable, the number of times per week individuals do light physical activity, is an ordinal variable for which the value of the outcome reflects relevant information. We may say that a higher value of the outcome variable is better than a lower value, since doing a higher number of light physical activity per weeks is better (in terms of health status benefits) than doing less light physical activity. Ideally, we would like to use this information provided by an ordinal variable, by estimating the effect of interest in an ordered response model. Unfortunately, in PSID database there is no information on how much time individuals spend in doing physical activity. That is, we know how many times per week they do physical activity but we do not know for how long they do physical activity in each reported session. In our database, an individual that reports doing light physical activity three times per week is not necessarily doing more light physical activity than an individual who reports one session per week.

Given this limitation, we use as the outcome variable a binary variable that reflects whether an individual does any positive number of light physical activity per week. 
In what follows, the outcome variable is:

$$
y_{i}= \begin{cases}0 & \text { if } \mathrm{i} \text { does not do light physical activity } \\ 1 & \text { if } \mathrm{i} \text { does light physical activity }\end{cases}
$$

The latent variable version of the model with three types of treatment has the following form:

$$
\begin{aligned}
y_{i t j}^{*}= & \beta_{0}+\beta_{1} \tau_{t}+\beta_{2} \text { elem }_{i}+\sum_{k=1}^{6} \beta_{3, k} S_{k}+ \\
& \beta_{4}\left(\text { elem }_{i} \times \tau_{t}\right)+\sum_{k=1}^{6} \beta_{5, k}\left(S_{k} \times \tau_{t}\right)+\sum_{k=1}^{6} \beta_{6, k}\left(S_{k} \times \text { elem }_{i}\right)+ \\
& \sum_{k=4}^{6} \beta_{7, k}\left(S_{k} \times \text { elem }_{i} \times \tau_{t}\right)+\beta_{8} X_{i t j}+u_{i t j},
\end{aligned}
$$

where $i=1 \ldots N$ indexes individuals, $t=0,1$ indexes time ( $0=$ before policy, $1999 ; 1=$ after policy, 2005), $j=1 \ldots 38$ indexes states and $k=1, . ., 6$ indexes state groups; $\tau_{t}$ is a dummy variable, equal one in 2005; $S_{k}$ is a dummy equal one if the individual resides in the state $j$ that belongs to group $k$; elem $i$ is a dummy equal one if individual $i$ has children of elementaryschool-age (children aged between 6 and 10 years old); and $X_{i t j}$ is a set of observable individual characteristics including age, race, gender, marital status, number of children, children of high-school-age, education level, employment status, total family income level and state of residence.

This specification controls for time trend in the dependent variable $\left(\beta_{1}\right)$, for time-invariant characteristics of the treatment group $\left(\beta_{2}\right)$, and for time-invariant characteristics of the different groups of states $\left(\left\{\beta_{3, k}\right\}_{k=1}^{6}\right)$. The second-level interactions control for changes over time for the treatment group nationwide $\left(\beta_{4}\right)$, changes over time in each group of states $\left(\left\{\beta_{5, k}\right\}_{k=1}^{6}\right)$, and time-invariant characteristics of the treatment group in each group of states $\left(\left\{\beta_{6, k}\right\}_{k=1}^{6}\right)$. The third-level interactions $\left(\left\{\beta_{7, k}\right\}_{k=4}^{6}\right)$ capture variation in the relative probability of physical activity specific to the treatments (relative to controls) in the experimental states with respect to the non-experimental states in the year after the HED requirements 
changed. These are the DDD estimates and they capture the effects of the different policies.

Given the existence of different time trends on the frequency of light physical activity between females and males observed in Figure 2, the model we estimate also interacts the policies with a dummy variable that takes value 1 if the individual is female. The model with interactions by gender has the following form:

$$
\begin{aligned}
y_{i t j}^{*}= & \beta_{0}+\beta_{1} \tau_{t}+\beta_{2} \text { elem }_{i}+\sum_{k=1}^{6} \beta_{3, k} S_{k}+\beta_{4} \text { female }_{i}+\beta_{5}\left(\tau_{t} \times \text { female }_{i}\right)+\beta_{6}\left(\text { elem }_{i} \times \text { female }_{i}\right)+ \\
& \sum_{k=1}^{6} \beta_{7, k}\left(S_{k} \times \text { female }_{i}\right)+\beta_{8}\left(\text { elem }_{i} \times \tau_{t}\right)+\beta_{9}\left(\text { elem }_{i} \times \tau_{t} \times \text { female }_{i}\right)+\sum_{k=1}^{6} \beta_{10, k}\left(S_{k} \times \tau_{t}\right)+ \\
& \sum_{k=1}^{6} \beta_{11, k}\left(S_{k} \times \tau_{t} \times \text { female }_{i}\right)+\sum_{k=1}^{6} \beta_{12, k}\left(S_{k} \times \text { elem }_{i}\right)+\sum_{k=1}^{6} \beta_{13, k}\left(S_{k} \times \text { elem }_{i} \times \text { female }_{i}\right)+ \\
& \sum_{k=4}^{6} \beta_{14, k}\left(S_{k} \times \text { elem }_{i} \times \tau_{t}\right)+\sum_{k=4}^{6} \beta_{15, k}\left(S_{k} \times \text { elem }_{i} \times \tau_{t} \times \text { female }_{i}\right)+\beta_{16} X_{i t j}+u_{i t j} .
\end{aligned}
$$

The DDD estimates in this model are $\beta_{14, k}$ for males, and $\beta_{14, k}+\beta_{15, k}$ for females. If the coefficient $\beta_{15, k}$ is significantly different from zero, then there is evidence of a differential impact of HED policies among fathers and mothers. We estimate the parameters of interest by Maximum-Likelihood and we compute standard errors corrected for cluster at family level. A report of the estimated coefficients can be found in Table 13 in the Appendix.

\section{IATE estimates}

In this Section we report the estimates of the Indirect Average Treatment Effect (IATE). The IATE is computed as the average value of the indirect treatment effect across treated individuals.

Let $\hat{\pi}_{k}=\left(\beta_{0}, \beta_{1}, \beta_{2},\left\{\beta_{3, k}\right\}_{k=1}^{6}, \beta_{4},\left\{\beta_{5, k}\right\}_{k=1}^{6},\left\{\beta_{6, k}\right\}_{k=1}^{6}, \beta_{8}\right)$ be the vector of estimated parameters without including the parameters that measure policy effects $\left(\left\{\beta_{7, k}\right\}_{k=4}^{6}\right)$. Similarly, let $Z_{i t j}$ be the vector of variables for the individual $i$ at time $t=2005$ residing in state $j$ without including the third level interaction variable $S_{k} \times e l e m_{i} \times \tau_{t}$.

The IATE across treated individuals in the group of states $S_{k}$ is computed using the following expression: 


$$
\sum_{i: \text { elem }=1 \& S_{k}=1}\left[\Phi\left(\hat{\pi}_{k} Z_{k i t}+\beta_{7, k}\left(S_{k} \times \text { elem }_{i} \times \tau_{t}\right)\right)-\Phi\left(\hat{\pi}_{k} Z_{k i t}\right)\right] / N_{k t},
$$

where $\Phi$ stands for the normal distribution function, and $N_{k t}$ is the number of treated individuals in the group of states $S_{k}$ at time $t=2005$.

We report in Table 5 the IATE for the three different types of treatment.

\begin{tabular}{l|rrrrrr}
\multicolumn{7}{c}{ Table 5: IATE across treated individuals. } \\
& $\begin{array}{c}\text { Male } \\
\text { OLS }\end{array}$ & $\begin{array}{l}\text { Probit } \\
\text { \# obs }\end{array}$ & OLS & Probit & \# obs \\
\hline \hline S4: Topics unchanged \& & -0.016 & -0.031 & 85 & -0.049 & -0.041 & 124 \\
Enforcements increase & $(0.071)$ & $(0.079)$ & & $(0.064)$ & $(0.071)$ & \\
& & & & & & \\
S5: Topics introduced \& & $\mathbf{0 . 1 0 2}^{*}$ & $\mathbf{0 . 1 4 2}$ & 157 & -0.011 & -0.018 & 215 \\
Enforcements introduced & $(0.057)$ & $(0.083)$ & & $(0.047)$ & $(0.055)$ & \\
& & & & & & \\
S6: Topics increase \& & 0.070 & -0.018 & 29 & 0.0003 & 0.014 & 47 \\
Enforcements increase & $(0.091)$ & $(0.140)$ & & $(0.091)$ & $(0.1759)$ & \\
\hline \hline
\end{tabular}

Cluster set at family level. Bootstrap standard errors with 1000 replications. The regression includes the following covariates: age, race, gender, marital status, number of children, children of high school-age, education level, employment status, total family income level, and state of residence. Significance levels: ${ }^{*}=10 \% ;{ }^{* *}=5 \% ;{ }^{* * *}=1 \%$.

We find evidence of a positive effect of HED education at elementary school on parents' probability of engaging in light physical activity. Requiring topics and enforcements for the first time ( $S_{5}$ group of states) raises fathers' probability of doing physical activity. Looking at the results of the probit model we can see that the probability of doing physical activity for a father affected by this policy is 14.2 percentage points higher than a comparable father not affected by the policy. The positive and statistically significant effect on fathers is also obtained by using a linear probability model. The effect on mothers' probability of physical activity is never statistically significant, but interestingly the signs are the opposite of those found for fathers.

The estimated effects are not statistically significant for males and females residing in groups of states $S_{4}$ and $S_{5}$. These results suggest that once the HED has been implemented, changes in its implementation does not have an additional indirect effect.

We conclude that there are positive spillovers of the implementation of HED for the first time on fathers' probability of doing physical activity, while for mothers we do not find a 
statistically significant effect of these reforms.

\subsection{Plausible explanations for our results}

We can think of two channels explaining our results. When children start receiving HED at school they parents are confronted with two new sets of factors that might potentially affect their health-related behavior. First, parents may optimally react to HED in schools by complementing this education with the incorporation of healthy lifestyles into their own daily activities. We refer to this potential channel as "role modeling". On the other hand, there is the effect of the arrival of new information that the child receives at the school. In particular, parents are faced up to the knowledge that the child brings to the household from the health education curricula given at the school, and they may adjust their health behaviors in response to it. We refer to this potential channel as "information sharing".

In what follows we provide evidence on the existence of both channels.

\subsubsection{Role models}

Parents may do more physical exercise in response to the knowledge children acquired via HED, not because they weren't aware of the benefits of exercising but because they want to complement the instruction received by the child so as to form the desired healthy lifestyle in the child.

The estimates from the model interacting the policies with a dummy variable for gender allow us to obtain some insights on the operation of the "role model" channel. Parents usually spend more time with their children doing gendered activities. Figure 3 in the Appendix shows some evidence in this respect with data coming from the American Time Use Survey (ATUS). Women spend roughly twice as much time in childcare as do men, a pattern which holds true for all subgroups and for almost all types of childcare, except for "Recreational" childcare. This type of childcare activities includes playing games with children, playing outdoors with children, attending a child's sporting event or dance recital, going to the zoo with children, taking walks with children, etc. In the case of "Recreational" childcare, mothers allocate relatively less of their time with children when compared with the time allocation into types of childcare activities that fathers do. Thus, this is evidence on the fact that fathers are more 
likely to do stereotypically male activities with their children, among which physical activity is included. Accordingly, the impact of HED reforms on physical activity is also expected to appear for fathers rather than for mother.

\subsubsection{Information sharing between children and parents}

Individuals with lower stock of information are expected to be more affected by HED changes. We explore the existence of the information sharing channel by analyzing the differential impact of HED reforms on individuals with low and high education levels and with low and high income levels. Since lower level of education and socioeconomic status are related with less knowledge about health (Tinsley, 2003), we expect to obtain a higher effect of HED reforms on individuals with lower level of education and income.

Exploiting the non linearity of the model specified we estimate IATE evaluated at particular values of the covariates of interest. We report the results in Table 6 for treated fathers residing in states that belong to group $S_{5}$. According to these results, the policy has a higher effect on low educated males relative to high educated males, on non-white males relative to white males, and on males that have a lower income than those having a higher income. The policy rises in 4 percentage points more the probability of being physically active of low educated males relative to high educated males, whereas the increment was 3.8 percentage points higher for non-white males relative to white males.

Table 6: Differences in IATE estimates evaluated at particular values of the covariates.

\begin{tabular}{lr|lr|rr} 
Income & IATE & Education & IATE & Race & IATE \\
\hline Low & $0.145^{*}$ & Low & $0.158^{*}$ & No White & $0.164^{*}$ \\
$(20$ th percentile) & $(0.085)$ & & $(0.090)$ & & $(0.093)$ \\
& & & & & \\
High & $0.140^{*}$ & High & 0.117 & White & 0.126 \\
$(80$ th percentile) & $(0.083)$ & & $(0.072)$ & & $(0.077)$ \\
\hline Difference & $\mathbf{0 . 0 0 4 *}$ & & $\mathbf{0 . 0 4 1 ^ { * * }}$ & & $\mathbf{0 . 0 3 8 ^ { * * }}$ \\
& $(0.002)$ & & $(0.020)$ & & $(0.018)$
\end{tabular}

Cluster set at family level. Bootstrap standard errors with 1000 replications. We find no differences for males in family size, labor force participation, and marital status. There exist no differences for females in all the dimensions analyzed. Significance levels: $*=10 \% ;{ }^{* *}=5 \%$; ${ }^{* *}=1 \%$. 


\section{Conclusion}

We find evidence on the existence of positive spillovers of HED imparted in elementary schools on parents' probability of engaging in light physical activity. However, our results suggest that fathers and not mothers are those affected by the HED reforms. We also analyze the differential impact of HED reforms on fathers and mothers as a way to explore the nature of the channels driving the spillovers.

We argue that the existence of a "role model" channel can explain the differential impact on fathers and mothers. The idea is based on the fact that there are different role models that mothers and fathers play for their children. Parents usually spend more time with their children doing gendered activities. Since physical activity can be included into the group of the typically male-activities, the effect of the promotion of the advantages of doing physical activity is more likely to appear for fathers rather than for mothers. We also explore the existence of a second channel driving our results -the "information sharing" channel- by analyzing the differential impact of HED reforms on individuals with low and high education levels, and we obtained the expected higher effect on less educated individuals and individuals with a lower socioeconomic status.

Our results also highlight the importance of clearly distinguishing the existence of several dimensions in the implementation of a policy. In our case, considering the two dimensions in the HED reforms -changes in topics and enforcements- as well as the distinction between implementing requirements for the first time relative to reforms in already existing requirements is important for the policy evaluation. Our main result shows the existence of spillovers only in the case when both policy dimensions are simultaneously implemented for the first time.

The existence of spillovers of HED on parental lifestyles indicates that the interaction between children and parents play a role in the formation of healthy lifestyles inside the household. Therefore, taking into account these spillovers is important in the cost-benefit analysis of introducing health education at schools. In addition, the conclusion that implementing reforms in topics is not enough to obtain spillovers at the family level helps to properly design policy interventions aiming to increase the acquisition of healthy lifestyles in a given community. 


\section{References}

Angelucci, M. And G. D. Giorgi (2009): "Indirect Effects of an Aid Program: How Do Cash Transfers Affect Ineligibles' Consumption?" American Economic Review, 99, $486-508$

Bhattacharya, J., J. Currie, and S. J. Haider (2006): "Breakfast of Champions?: The School Breakfast Program and the Nutrition of Children and Families," J. Human Resources, XLI, 445-466.

Cawley, J., C. Meyerhoefer, And D. Newhouse (2007): "The impact of state physical education requirements on youth physical activity and overweight," Health Economics, 16, $1287-1301$

Clark, A. E. And F. Etile (2006): "Don't give up on me baby: Spousal correlation in smoking behaviour," Journal of Health Economics, 25(5), 958-978.

Currie, J. (2009): "Healthy, Wealthy, and Wise: Socioeconomic Status, Poor Health in Childhood, and Human Capital Development," Journal of Economic Literature, 47, 87122.

Gruber, J. (1994): "The Incidence of Mandated Maternity Benefits," American Economic Review, 84, 622-41.

Guryan, J., E. Hurst, And M. Kearney (2008): "Parental education and parental time with children," Journal of Economic Perspectives, 22, 23-46.

JACOBY, H. G. (2002): "Is There an Intrahousehold "Flypaper Effect"? Evidence From a School Feeding Programme," Economic Journal, 112, 196-221.

Kann, L., N. D. Brener, And D. Allensworth (2001): "Health education: results from the School Health Policies and Programs Study 2000," Journal of School Health, 71, $266-278$

Kann, L., S. Telluohann, and S. Wooley (2007): "Health Education: Results from the School Health Policies and Programs Study 2006," Journal of School Health, 77, 408-434. 
Kenkel, D. S. (2000): "Prevention," Handbook of Health Economics, 1, 1675-1720.

Lalive, R. And A. Cattaneo (2006): "Social Interactions and Schooling Decisions," IZA Discussion Papers 2250, Institute for the Study of Labor (IZA).

MCGeary, K. A. (2009): "The Impact of State-Level Nutrition-Education Program Funding on BMI: Evidence from the Behavioral Risk Factor Surveillance System," NBER Working Papers 15001, National Bureau of Economic Research, Inc.

Miguel, E. AND M. Kremer (2004): "Worms: Identifying Impacts on Education and Health in the Presence of Treatment Externalities," Econometrica, 72, 159-217.

SHI, X. (2008): "Does an intra-household flypaper effect exist? Evidence from the educational fee reduction reform in rural China," mimeo.

Tinsley, B. J. (2003): How children learn to be healthy, Cambridge University Press.

WHO (1999): "Improving health through schools: national and international strategies," http : //www.who.int/school outh $_{h}$ ealth/media/en/94.pdf.

(2003): "Health and Development Through Physical Activity and Sport," http : //whqlibdoc.who.int/hq/2003/WHO_NMH_NPH_PAH_03.2.pdf.

Wyatt, T. AND J. NovaK (2000): "Collaborative partnerships: a critical element in school health programs," Family \& Community Health, 23, 1. 


\section{Appendix}

Table 7: States That Require Elementary Schools to Teach Health Topics, by Topic and Year

\begin{tabular}{|c|c|c|c|c|c|c|c|c|c|c|}
\hline State & topic 1 & topic 2 & $\begin{array}{c}2000 \\
\text { topic } 3\end{array}$ & topic 4 & topic 5 & topic 1 & topic 2 & $\begin{array}{c}2006 \\
\text { topic } 3\end{array}$ & topic 4 & topic 5 \\
\hline Alabama & yes & yes & yes & yes & yes & yes & yes & yes & yes & yes \\
\hline Alaska & no & no & no & no & no & no & no & no & no & no \\
\hline Arizona & no & no & no & no & no & no & no & no & no & no \\
\hline Arkansas & no & no & no & no & no & no & no & yes & yes & no \\
\hline California & yes & yes & yes & yes & yes & yes & yes & yes & no & yes \\
\hline Colorado & no & no & no & no & no & no & no & no & no & no \\
\hline Connecticut & yes & yes & yes & yes & yes & yes & yes & yes & yes & yes \\
\hline Delaware & yes & yes & yes & yes & yes & yes & yes & yes & yes & yes \\
\hline District of Columbia & yes & yes & yes & yes & yes & yes & yes & yes & yes & yes \\
\hline Florida & no & no & no & no & no & yes & yes & yes & no & no \\
\hline Georgia & yes & yes & yes & no & yes & yes & yes & yes & yes & yes \\
\hline Hawaii & no & no & no & yes & no & yes & yes & yes & yes & yes \\
\hline Idaho & no & no & no & no & no & yes & yes & yes & yes & yes \\
\hline Illinois & yes & yes & yes & yes & yes & yes & yes & yes & yes & yes \\
\hline Indiana & yes & yes & yes & yes & yes & yes & yes & yes & no & yes \\
\hline Iowa & yes & yes & yes & yes & yes & yes & no & yes & no & yes \\
\hline Kansas & no & no & no & no & no & no & no & no & no & no \\
\hline Kentucky & yes & yes & yes & yes & yes & yes & yes & yes & yes & yes \\
\hline Louisiana & yes & yes & yes & yes & yes & yes & yes & yes & no & yes \\
\hline Maine & yes & yes & yes & no & yes & yes & yes & yes & yes & yes \\
\hline Maryland & yes & yes & yes & yes & yes & yes & yes & yes & yes & yes \\
\hline Massachusetts & yes & yes & yes & yes & yes & yes & yes & yes & yes & yes \\
\hline Michigan & yes & yes & yes & no & yes & yes & yes & yes & no & yes \\
\hline Minnesota & yes & no & yes & yes & yes & no & no & no & no & no \\
\hline Mississippi & yes & yes & yes & yes & yes & no & no & no & yes & no \\
\hline Missouri & yes & yes & yes & yes & yes & yes & no & no & no & yes \\
\hline Montana & yes & yes & yes & yes & yes & yes & yes & yes & yes & yes \\
\hline Nebraska & yes & no & no & no & yes & yes & no & yes & yes & yes \\
\hline Nevada & yes & yes & yes & yes & yes & yes & no & yes & yes & yes \\
\hline New Hampshire & yes & yes & yes & yes & no & yes & no & no & no & no \\
\hline New Jersey & yes & yes & yes & yes & yes & yes & yes & yes & no & yes \\
\hline New Mexico & no & no & no & no & no & yes & yes & yes & yes & yes \\
\hline New York & yes & yes & yes & yes & yes & yes & yes & yes & yes & yes \\
\hline North Carolina & yes & yes & yes & yes & yes & yes & yes & yes & yes & yes \\
\hline North Dakota & yes & no & no & no & yes & yes & no & no & yes & yes \\
\hline Ohio & yes & no & yes & yes & yes & no & no & no & no & no \\
\hline Oklahoma & yes & yes & yes & yes & yes & no & no & no & no & no \\
\hline Oregon & yes & yes & yes & yes & yes & yes & no & no & no & yes \\
\hline Pennsylvania & yes & no & no & no & yes & yes & yes & yes & yes & yes \\
\hline Rhode Island & yes & yes & yes & yes & yes & yes & yes & yes & yes & yes \\
\hline South Carolina & yes & yes & yes & yes & yes & yes & yes & yes & yes & yes \\
\hline South Dakota & no & no & no & no & no & no & no & no & no & no \\
\hline Tennessee & yes & yes & yes & yes & yes & yes & yes & yes & yes & yes \\
\hline Texas & no & no & no & no & no & yes & yes & yes & yes & yes \\
\hline Utah & yes & yes & yes & yes & yes & yes & yes & yes & yes & yes \\
\hline Vermont & yes & yes & yes & no & yes & yes & yes & yes & yes & yes \\
\hline Virginia & yes & yes & yes & yes & yes & yes & yes & yes & yes & yes \\
\hline Washington & yes & no & yes & yes & yes & yes & yes & yes & yes & yes \\
\hline West Virginia & yes & yes & yes & yes & yes & yes & yes & yes & yes & yes \\
\hline Wisconsin & yes & yes & no & no & yes & no & no & no & no & no \\
\hline Wyoming & no & no & no & no & no & no & yes & no & no & no \\
\hline
\end{tabular}

Source: School Health Policies and Programs Study (SHPPS).

Topic 1:Alcohol or other drug-use prevention; Topic 2: Emotional and mental health; Topic 3: Nutrition and dietary behavior;

Topic 4: Physical activity and fitness; Topic 5: Tabacco-use prevention. 
Table 8: States That Implemented Enforcements, by Enforcement and Year

\begin{tabular}{|c|c|c|c|c|c|c|}
\hline State & Enf 1 & $\begin{array}{c}2000 \\
\text { Enf } 2\end{array}$ & Enf 3 & Enf 1 & $\begin{array}{c}2006 \\
\text { Enf } 2\end{array}$ & Enf 3 \\
\hline Alabama & yes & no & no & yes & no & yes \\
\hline Alaska & no & no & no & yes & no & no \\
\hline Arizona & yes & no & no & yes & no & no \\
\hline Arkansas & yes & no & no & yes & no & no \\
\hline California & no & no & no & no & no & no \\
\hline Colorado & no & no & no & no & no & no \\
\hline Connecticut & no & no & no & no & no & no \\
\hline Delaware & yes & no & yes & yes & no & yes \\
\hline D. of Columbia & no & yes & yes & yes & no & yes \\
\hline Florida & yes & no & no & yes & no & no \\
\hline Georgia & yes & no & no & yes & no & no \\
\hline Hawaii & yes & yes & no & yes & no & no \\
\hline Idaho & no & no & no & yes & yes & yes \\
\hline Illinois & yes & no & no & yes & no & no \\
\hline Indiana & yes & no & no & yes & no & no \\
\hline Iowa & no & no & no & no & no & no \\
\hline Kansas & no & no & no & no & no & no \\
\hline Kentucky & no & yes & no & yes & yes & no \\
\hline Louisiana & yes & no & no & yes & no & no \\
\hline Maine & yes & yes & no & yes & yes & no \\
\hline Maryland & yes & no & no & yes & no & no \\
\hline Massachusetts & yes & no & no & no & no & no \\
\hline Michigan & yes & no & no & yes & no & no \\
\hline Minnesota & yes & no & no & no & no & no \\
\hline Mississippi & yes & no & no & yes & no & no \\
\hline Missouri & yes & yes & no & yes & yes & no \\
\hline Montana & yes & no & no & yes & no & no \\
\hline Nebraska & no & no & no & no & no & no \\
\hline Nevada & yes & no & no & yes & no & no \\
\hline New Hampshire & no & no & no & no & no & no \\
\hline New Jersey & yes & yes & no & yes & no & no \\
\hline New Mexico & yes & yes & no & yes & no & no \\
\hline New York & yes & no & yes & yes & no & no \\
\hline North Carolina & yes & no & no & yes & no & no \\
\hline North Dakota & no & no & no & no & no & no \\
\hline Ohio & no & no & no & no & no & no \\
\hline Oklahoma & no & no & no & yes & no & no \\
\hline Oregon & no & no & no & yes & no & no \\
\hline Pennsylvania & yes & no & no & yes & yes & yes \\
\hline Rhode Island & yes & yes & no & yes & yes & yes \\
\hline South Carolina & yes & no & no & yes & yes & no \\
\hline South Dakota & no & no & no & no & no & no \\
\hline Tennessee & yes & no & no & yes & no & no \\
\hline Texas & no & no & no & yes & no & no \\
\hline Utah & yes & no & no & yes & yes & no \\
\hline Vermont & yes & no & no & yes & yes & no \\
\hline Virginia & no & no & no & yes & no & no \\
\hline Washington & yes & yes & no & yes & yes & no \\
\hline West Virginia & yes & no & no & yes & no & no \\
\hline Wisconsin & no & no & no & no & no & yes \\
\hline Wyoming & no & no & no & yes & no & no \\
\hline
\end{tabular}

Source: School Health Policies and Programs Study (SHPPS).

Enforcement 1: State requires districts or schools to follow national or state health education standards or guidelines.

Enforcement 2: State requires students in elementary school to be tested on health topics.

Enforcement 3: State requires each school to have a HED coordinator. 
Table 9: Number of Topics and Enforcements, by State and Year

\begin{tabular}{|c|c|c|c|c|}
\hline State & $\begin{array}{l}\text { topics } \\
2000\end{array}$ & $\begin{array}{l}\text { topics } \\
2006\end{array}$ & $\begin{array}{c}\text { enforcements } \\
2000\end{array}$ & $\begin{array}{c}\text { enforcements } \\
2006\end{array}$ \\
\hline Alabama & 5 & 5 & 1 & 2 \\
\hline Alaska & 0 & 0 & 0 & 1 \\
\hline Arizona & 0 & 0 & 1 & 1 \\
\hline Arkansas & 0 & 2 & 1 & 1 \\
\hline California & 5 & 4 & 0 & 0 \\
\hline Colorado & 0 & 0 & 0 & 0 \\
\hline Connecticut & 5 & 5 & 0 & 0 \\
\hline Delaware & 5 & 5 & 2 & 2 \\
\hline District of Columbia & 5 & 5 & 2 & 2 \\
\hline Florida & 0 & 3 & 1 & 1 \\
\hline Georgia & 4 & 5 & 1 & 1 \\
\hline Hawaii & 1 & 5 & 2 & 1 \\
\hline Idaho & 0 & 5 & 0 & 3 \\
\hline Illinois & 5 & 5 & 1 & 1 \\
\hline Indiana & 5 & 4 & 1 & 1 \\
\hline Iowa & 5 & 3 & 0 & 0 \\
\hline Kansas & 0 & 0 & 0 & 0 \\
\hline Kentucky & 5 & 5 & 1 & 2 \\
\hline Louisiana & 5 & 4 & 1 & 1 \\
\hline Maine & 4 & 5 & 2 & 2 \\
\hline Maryland & 5 & 5 & 1 & 1 \\
\hline Massachusetts & 5 & 5 & 1 & 0 \\
\hline Michigan & 4 & 4 & 1 & 1 \\
\hline Minnesota & 4 & 0 & 1 & 0 \\
\hline Mississippi & 5 & 1 & 1 & 1 \\
\hline Missouri & 5 & 2 & 2 & 2 \\
\hline Montana & 5 & 5 & 1 & 1 \\
\hline Nebraska & 2 & 4 & 0 & 0 \\
\hline Nevada & 5 & 4 & 1 & 1 \\
\hline New Hampshire & 4 & 1 & 0 & 0 \\
\hline New Jersey & 5 & 4 & 2 & 1 \\
\hline New Mexico & 0 & 5 & 2 & 1 \\
\hline New York & 5 & 5 & 2 & 1 \\
\hline North Carolina & 5 & 5 & 1 & 1 \\
\hline North Dakota & 2 & 3 & 0 & 0 \\
\hline Ohio & 4 & 0 & 0 & 0 \\
\hline Oklahoma & 5 & 0 & 0 & 1 \\
\hline Oregon & 5 & 2 & 0 & 1 \\
\hline Pennsylvania & 2 & 5 & 1 & 3 \\
\hline Rhode Island & 5 & 5 & 2 & 3 \\
\hline South Carolina & 5 & 5 & 1 & 2 \\
\hline South Dakota & 0 & 0 & 0 & 0 \\
\hline Tennessee & 5 & 5 & 1 & 1 \\
\hline Texas & 0 & 5 & 0 & 1 \\
\hline Utah & 5 & 5 & 1 & 2 \\
\hline Vermont & 4 & 5 & 1 & 2 \\
\hline Virginia & 5 & 5 & 0 & 1 \\
\hline Washington & 4 & 5 & 2 & 2 \\
\hline West Virginia & 5 & 5 & 1 & 1 \\
\hline Wisconsin & 3 & 0 & 0 & 1 \\
\hline Wyoming & 0 & 1 & 0 & 1 \\
\hline
\end{tabular}

Source: School Health Policies and Programs Study (SHPPS). 
Table 10: HED topics and enforcements - Full list

\section{Topics List}

1) Alcohol- or Other Drug-Use Prevention

2) Emotional and Mental Health

3) Nutrition and Dietary Behavior

4) Physical Activity and Fitness

5) Tobacco-Use Prevention

6) Human immunodeficiency virus (HIV) prevention

7) Accident or injury prevention

8) Sexually transmitted disease (STD) prevention

9) Pregnancy prevention

10) Suicide prevention

11) Violence prevention, for example bullying, fighting, or homicide

\section{Enforcements List}

1) State requires districts or schools to follow national or state health education standards or guidelines

2) State requires students in elementary school to be tested on health topics

3) State requires each school to have a HED coordinator

4) State uses staff development for health education teachers to improve compliance with health education standards or guidelines

5) State uses written reports from districts or schools to document compliance with health education standards or guidelines

6) State provides a list of one or more recommended elementary school health education curricula

7) State provides a chart describing the scope and sequence of instruction for elementary school health education

8) State provides lesson plans or learning activities for elementary school health education

9) State provides plans for how to assess or evaluate students in elementary school health education

10) State adopts a policy stating that newly hired staff who teach health education at the elementary school level will have undergraduate or graduate training in health education 11) State offers certification, licensure, or endorsement to teach health education

12) State adopts a policy stating that teachers will earn continuing education credits on health education topics to maintain state certification, licensure, or endorsement to teach health education

In Italic topic and enforcements considered for the analysis. 
Table 11: States classified by groups $S_{k}$

NON-EXPERIMENTAL

EXPERIMENTAL

\begin{tabular}{l|c|l|c} 
State & \# of obs. & State & \# of obs. \\
\hline $\mathbf{S}_{\mathbf{1}}$ & & & \\
Alaska & & S $_{\mathbf{4}}$ & \\
Colorado & 224 & Alabama & 128 \\
Kansas & 70 & Kentucky & 170 \\
Mississippi & 498 & Rhode Island & 196 \\
Oklahoma & 61 & South Carolina & 543 \\
South Dakota & 56 & Utah & 93 \\
& & & \\
$\mathbf{S}_{\mathbf{2}}$ & & S $_{\mathbf{5}}$ & \\
California & 1,133 & Arkansas & 261 \\
Connecticut & 76 & Florida & 424 \\
Iowa & 244 & Georgia & 391 \\
Ohio & 487 & Idaho & 25 \\
Tennessee & 229 & Maine & 30 \\
Virginia & 347 & Minnesota & 167 \\
& & Nevada & 67 \\
S3 & & Texas & 640 \\
Delaware & 12 & Wyoming & 16 \\
District of Columbia & 63 & & \\
Illinois & 376 & S & \\
Indiana & 341 & Pennsylvania & 453 \\
Louisiana & 188 & Vermont & 7 \\
Maryland & 431 & & \\
Massachusetts & 253 & & \\
Michigan & 571 & & \\
Missouri & 324 & & \\
Montana & 13 & & \\
New Jersey & 316 & & \\
New York & 461 & & \\
North Carolina & 532 & & \\
Washington & 202 & & \\
West Virginia & 23 & & \\
Wisconsin & 175 & & \\
& & & \\
\hline
\end{tabular}

States' classification made using NASBE database and SHPPS surveys.

We do not include in the sample Arizona, Hawaii, Nebraska, New Mexico, and North Dakota because sample sizes in these states are small. 
Table 12: DDD estimator for females in $S_{5}$

Before HED After HED Time

change change difference

A. Treatment individuals: with children in elem

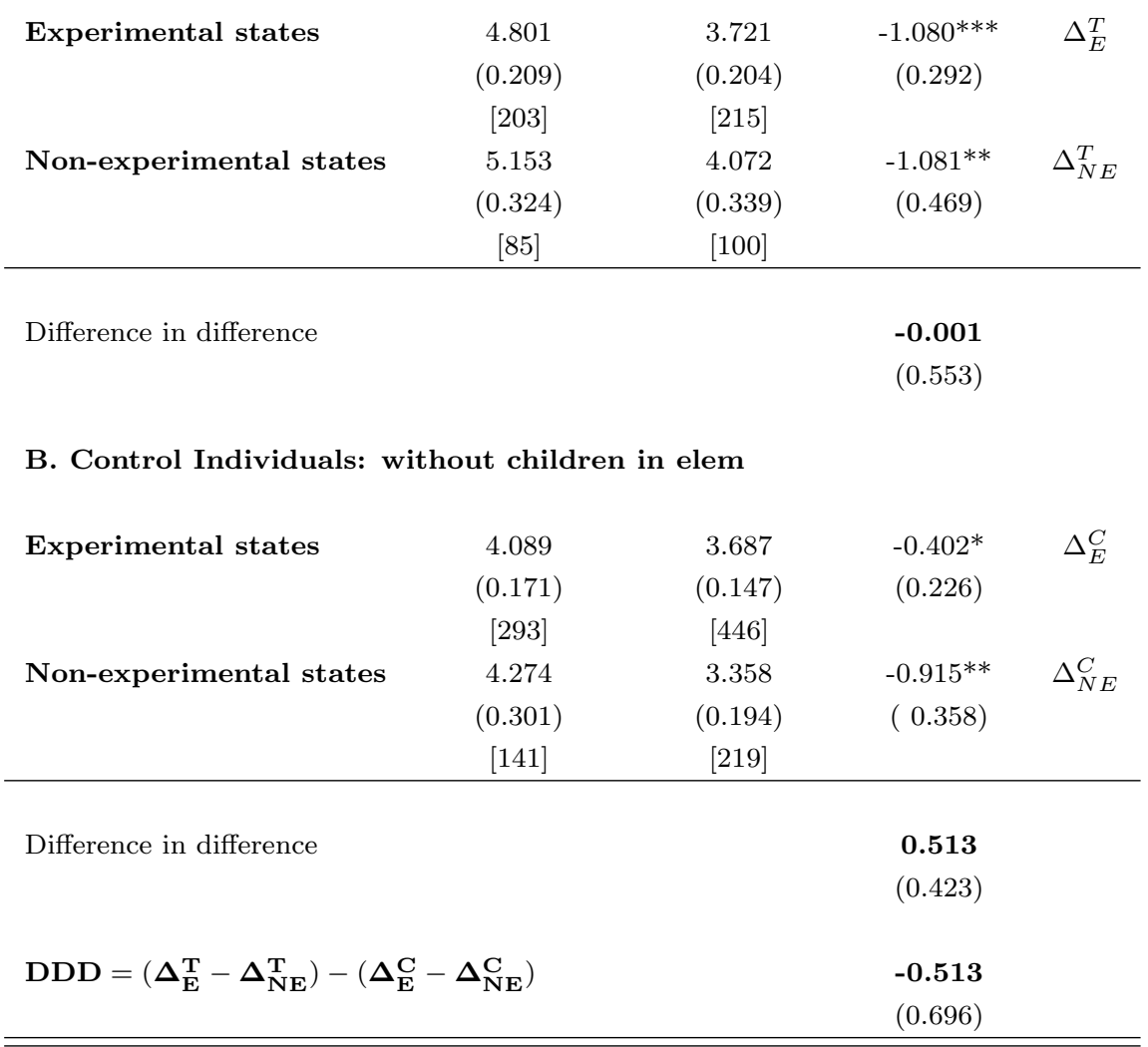

Cells contain mean frequency of light physical activity for the group identified. Standard errors are given in parentheses, and sample sizes in brackets. The non-experimental states are groups of states S0, S1 and S2. Significance levels: $*=10 \% ; * *=5 \%$; ** $=1 \%$.

The upper part of Table 12 shows important falls in temporal trends of the frequency of light physical activity for mothers of children of elementary school age residing in both, experimental and non-experimental states. As a consequence the difference-in-difference estimator is not statistically significant. We can observe a similar pattern for mothers of children bellow and above elementary school age. Finally, the triple difference estimator does not provide evidence of an effect of HED on mothers' frequency of light physical activity. 
Table 13: Probit Model: probability of doing light physical activity

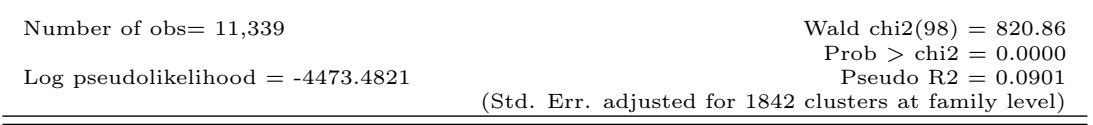

\begin{tabular}{|c|c|c|c|c|c|}
\hline Variable & Coefficient & (Std. Err.) & Variable & Coefficient & (Std. Err.) \\
\hline tau & -0.254 & $(0.187)$ & married & $0.099^{*}$ & $(0.056)$ \\
\hline elem & 0.129 & $(0.191)$ & widowed & -0.112 & $(0.186)$ \\
\hline $\mathrm{S} 2$ & -0.205 & $(0.223)$ & divorced & 0.060 & $(0.070)$ \\
\hline S3 & -0.169 & $(0.265)$ & separated & -0.030 & $(0.084)$ \\
\hline $\mathrm{S} 4$ & -0.123 & $(0.278)$ & nchildren & 0.003 & $(0.037)$ \\
\hline S5 & -0.225 & $(0.253)$ & nchildren $^{2}$ & 0.003 & $(0.005)$ \\
\hline S6 & -0.353 & $(0.331)$ & pclabinc & $0.026^{* * *}$ & $(0.008)$ \\
\hline elem_tau & -0.124 & $(0.121)$ & onleave & -0.198 & $(0.138)$ \\
\hline S2_tau & -0.030 & $(0.205)$ & unemployed & -0.055 & $(0.076)$ \\
\hline S3_tau & -0.084 & $(0.197)$ & retired & $-0.301^{*}$ & $(0.163)$ \\
\hline S4_tau & -0.112 & $(0.261)$ & disabled & $-0.540^{* * *}$ & $(0.083)$ \\
\hline S5_tau & -0.360 & $(0.237)$ & housekeeper & 0.081 & $(0.059)$ \\
\hline S6_tau & -0.302 & $(0.329)$ & student & $0.302^{* *}$ & $(0.137)$ \\
\hline S2_elem & 0.067 & $(0.200)$ & stated 2 & -0.062 & $(0.540)$ \\
\hline S3_elem & -0.026 & $(0.195)$ & stated 4 & 0.074 & $(0.123)$ \\
\hline S4_elem & 0.064 & $(0.308)$ & stated 7 & $-0.410^{*}$ & $(0.246)$ \\
\hline S5_elem & -0.327 & $(0.272)$ & stated 8 & -0.260 & $(0.451)$ \\
\hline S6_elem & 0.569 & $(0.543)$ & stated 11 & 0.064 & $(0.117)$ \\
\hline S4_elem_tau & -0.130 & $(0.344)$ & stated 13 & 0.221 & $(0.543)$ \\
\hline S5_elem_tau & $0.495^{*}$ & $(0.276)$ & stated 14 & -0.122 & $(0.175)$ \\
\hline S6_elem_tau & -0.105 & $(0.619)$ & stated 15 & -0.078 & $(0.194)$ \\
\hline tau_w & -0.031 & $(0.232)$ & stated 16 & -0.110 & $(0.137)$ \\
\hline elem_w & 0.170 & $(0.231)$ & stated 17 & -0.297 & $(0.211)$ \\
\hline S2_w & $0.398^{*}$ & $(0.226)$ & stated 18 & -0.142 & $(0.189)$ \\
\hline S3_w & 0.243 & $(0.211)$ & stated 19 & -0.031 & $(0.209)$ \\
\hline S4_w & 0.110 & $(0.254)$ & stated 20 & 0.024 & $(0.224)$ \\
\hline S5_w & -0.052 & $(0.246)$ & stated 21 & -0.064 & $(0.173)$ \\
\hline S6_w & 0.509 & $(0.321)$ & stated 22 & -0.255 & $(0.196)$ \\
\hline elem_tau_w & 0.017 & $(0.154)$ & stated 23 & -0.107 & $(0.172)$ \\
\hline S2_tau_w & -0.186 & $(0.257)$ & stated 24 & $0.432^{* *}$ & $(0.175)$ \\
\hline S3_tau_w & -0.104 & $(0.242)$ & stated 25 & $-0.354^{* *}$ & $(0.153)$ \\
\hline S4_tau_w & 0.124 & $(0.325)$ & stated 26 & -0.082 & $(0.176)$ \\
\hline S5_tau_w & 0.320 & $(0.293)$ & stated 27 & 0.192 & $(0.487)$ \\
\hline S6_tau_w & -0.301 & $(0.368)$ & stated 29 & 0.125 & $(0.197)$ \\
\hline S2_elem_w & -0.310 & $(0.238)$ & stated 31 & -0.250 & $(0.200)$ \\
\hline S3_elem_w & -0.216 & $(0.228)$ & stated 33 & -0.246 & $(0.177)$ \\
\hline S4_elem_w & -0.318 & $(0.384)$ & stated 34 & -0.079 & $(0.184)$ \\
\hline S5_elem_w & 0.201 & $(0.333)$ & stated 36 & -0.152 & $(0.096)$ \\
\hline S6_elem_w & -0.915 & $(0.617)$ & stated 37 & $-0.509^{*}$ & $(0.264)$ \\
\hline S4_elem_tau_w & -0.021 & $(0.448)$ & stated 38 & -0.079 & $(0.209)$ \\
\hline S5_elem_tau_w & $-0.566^{*}$ & $(0.333)$ & stated 41 & -0.228 & $(0.158)$ \\
\hline S6_elem_tau_w & 0.152 & $(0.713)$ & stated 42 & $-0.460^{* *}$ & $(0.229)$ \\
\hline jhs & $0.085^{* *}$ & $(0.038)$ & stated 43 & -0.050 & $(0.135)$ \\
\hline female & -0.156 & $(0.195)$ & stated 44 & 0.067 & $(0.107)$ \\
\hline age & -0.013 & $(0.013)$ & stated 45 & 0.333 & $(0.270)$ \\
\hline$a g e^{2}$ & 0.000 & $(0.000)$ & stated 47 & $-0.290^{* *}$ & $(0.119)$ \\
\hline white & $0.370^{* * *}$ & $(0.043)$ & stated 48 & -0.053 & $(0.193)$ \\
\hline \multirow[t]{4}{*}{ edu } & $0.065^{* * *}$ & $(0.007)$ & stated 49 & -0.212 & $(0.392)$ \\
\hline & & & stated50 & 0.250 & $(0.214)$ \\
\hline & & & stated51 & -0.488 & $(0.379)$ \\
\hline & & & Intercept & $0.572^{*}$ & $(0.321)$ \\
\hline
\end{tabular}

Significance levels: $*=10 \% ; * *=5 \% ; * * *=1 \%$.

Variable names: tau: time fix effect; elem: group of parent's of children of elementary school age fix effect (group fix effect); $S \_k$. groups of states $k$ fix effect (region fix effect); elem_tau: group time trend control (group-time interaction); $S_{k}$-tau: state time trend control (region-time interaction); $S_{k_{-}}$elem: region-group interaction; $S_{k_{-}}$elem_tau: DDD estimator of HED effect on region $k$; All variables of the form $X_{w}$ are $X$ variables interacted with gender dummy female; $j h s$ : number of children of secondary school age; age: age of in years; age ${ }^{2}$ : square of age; white: white race dummy; edu: year of education completed; married: married or permanently cohabiting dummy; widowed: widowed dummy; separated: separated dummy; divorced: legally divorced dummy; nchildren: number of children (all ages); nchildren ${ }^{2}$ : square of number of children; pclabinc: per-capita family labor income; onleave: only temporarily laid off, sick leave or maternity leave dummy; unemployed: looking for work, unemployed dummy; retired: retired dummy; disabled: permanently or temporarily disabled dummy; housekeeper: housekeeper dummy; student: student dummy; statedj: state $j$ fix effect. 
Figure 3: Ratios father-mother of means of time spent in childcare activities by different demographic subgroups (hours per week).

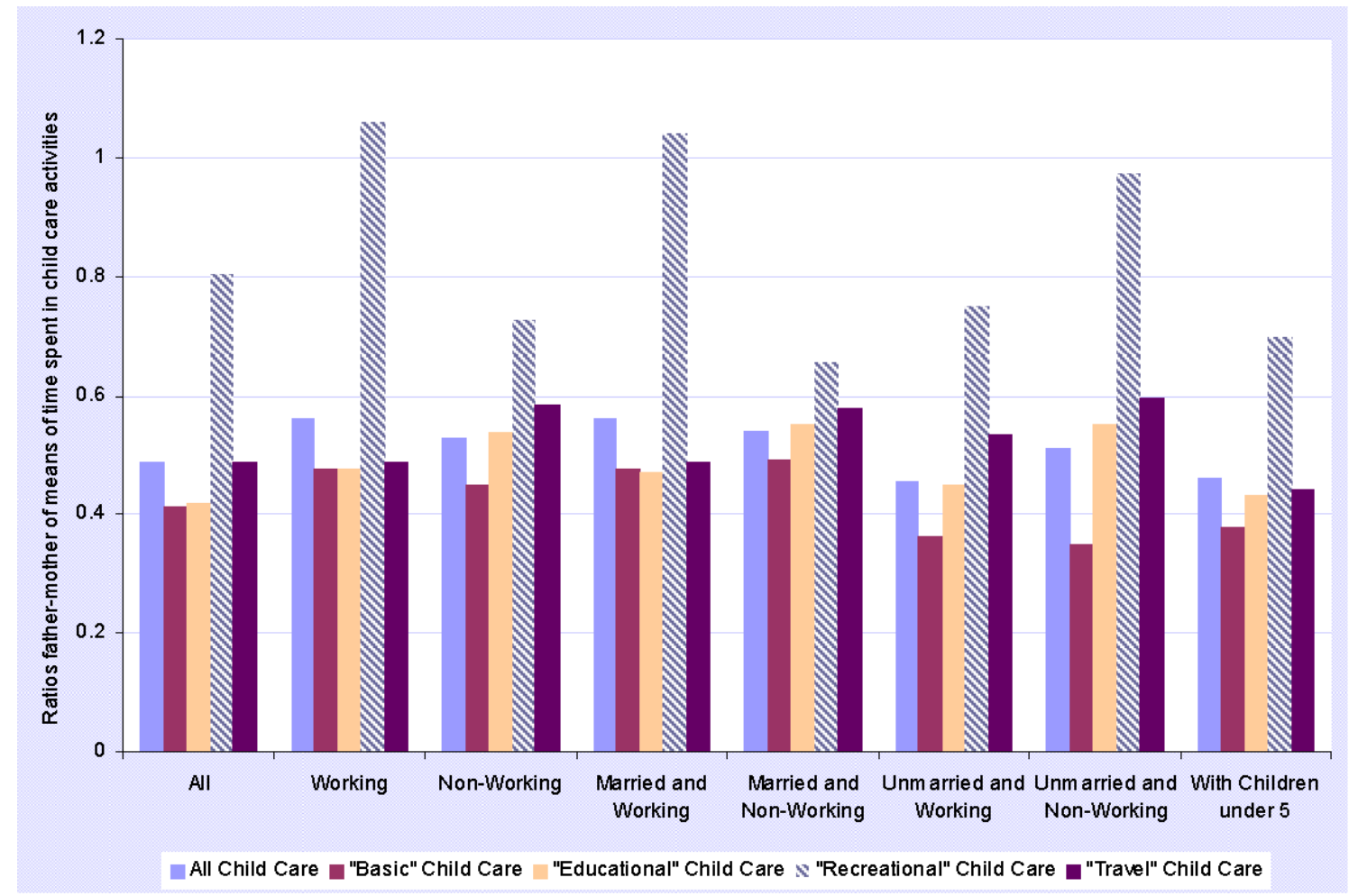

Source: Ratios computed using data in Table 1 in (Guryan et al., 2008) based on the 2003-2006 waves of the American Time Use Survey (ATUS). Childcare activities are classified into: "Basic" childcare (breast feeding, rocking a child to sleep, general feeding, changing diapers, providing medical care to child, grooming child, etc.); "Educational" childcare (reading to children, teaching children, helping children with homework, attending meetings at a child's school, etc.); "Recreational" childcare (playing games with children, playing outdoors with children, attending a child's sporting event or dance recital, going to the zoo with children, taking walks with children, etc.); "Travel" childcare (any travel related to any of the three other categories of childcare). Samples include all individuals between the ages of 21 and 55 (inclusive) who had time diaries summing to a complete day and at least one child under the age of 18. 